organism. For hours, and even for days after the operation, these motions persisted; so that the contrast between the death-like quiescence of the mutilated swimmingbell and the active contractions of the thread-like portion which had just been removed from its margin, was a contrast as striking as it is possible to conceive.

These experiments, then, conclusively proved that in the marginal rim of the Medusæ there is situated an in. tensely localised system of nervous centres, or ganglia, to the functional activity of which the rhythmical motions of the swimming-bell are exclusively due.

( $T$ o be continued.)

\section{ON ELEMENTARY INSTRUCTION IN PHYSIOLOGY}

THE chief ground upon which I venture to recommend that the teaching of elementary physiology should form an essential part of any organised course of instruction in matters pertaining to domestic economy, is that a knowledge of even the elements of this subject supplies those conceptions of the constitution and mode of action of the living body and of the nature of health and disease, which prepare the mind to receive instruction from sanitary science.

It is, I think, eminently desirable that the hygienist and the physician should find something in the public mind to which they can appeal; some little stock of universally acknowledged truths, which may serve as a foundation for their warnings, and predispose towards an intelligent obedience to their recommendations.

Listening to ordinary talk about health, disease, and death, one is often led to entertain a doubt whether the speakers believe that the course of natural causation runs as smoothly in the human body as elsewhere. Indications are too often obvious of a strong, though perhaps an unavowed and half unconscious, undercurrent of opinion that the phenomena of life are not only widely different in their superficial characters and in their practical importance, from other natural events; but that they do not follow in that definite order which characterises the succession of all other occurrences, and the statement of which we call a law of nature.

Hence, I think, arises the want of heartiness of belief in the value of knowledge respecting the laws of health and disease, and of the foresight and care to which knowledre is the essential preliminary, which is so often noticeable; and a corresponding laxity and carelessness in practice, the results of which are too frequently lamentable.

It is said that, among the many religious sects of Russia, there is one which holds that all disease is brought about by the direct and special interference of the Deity, and which, therefore, looks with repugnance upon both preventive and curative measures, as alike blasphemous interferences with the will of God. Among ourselves, the "Peculiar People" are, I believe, the only persons who hold the like doctrine in its integrity, and carry it out with logical rigour. But many of us are old enough to recollect that the administration of chloroform in assuagement of the pangs of childbirth was, at its introduction, strenuously resisted lipon similar grounds.

I am not sure that the feeling, of which the doctrine to which I have referred is the full expression, does not lie at the bottom of the minds of a great many people who would yet vigorously object to give a verbal assent to the doctrine itself. However this may be, the main point is that sufficient knowledge has now been acquired of vital phenomena to justify the assertion that the notion that there is anything exceptional about these phenomena receives not a particle of support from any known fact. r. A paper read at the Domestic Economy Congress, by Prof. Huxley,
F.R.S.
On the contrary, there is a vast and an increasing mass of evidence that birth and death, health and disease, are as much parts of the ordinary stream of events as the rising and setting of the sun, or the changes of the moon; and that the living body is a mechanism the proper working of which we term health ; its disturbance, disease ; its stoppage, death. The activity of this mechanism is dependent upon many and complicated conditions, some of which are hopelessly beyond our control, while others are reaclily accessible and are capable of being indefinitely modified by our own actions. The business of the hygienist and of the physician is to know the range of these modifiable conditions, and how to influence them towards the maintenance of health and the prolongation of life : the business of the general public is to give an intelligent assent and a ready oberlience based lipon that assent, to the rules laid down for their guidance by such experts. But an intelligent assent is an assent based upon knowledge, and the knowledge which is here in question means an acquaintance with the elements of physiology.

It is not difficult to acquire such knowledge. What is true, to a certain extent, of all the physical sciences, is eminently charactsristic of physiology-the difficulty of the subject begins beyond the stage of elementary knowledge, and increases with every stare of progress. While the most highly trained and best furnished intellect may find all its resources insufficient when it strives to reach the heights and penetrate into the depths of the problems of physiology, the elementary and fundamental truths can be made clear to a child.

No one can have any difficulty in comprehending the mechanism of circulation or respiration, or the general mode of operation of the organ of vision; though the unravelling of all the minutio of these processes may, for the present, baffle the conjoined attacks of the most accomplished physicists, chemists, and mathematicians. To know the anatomy of the human body, with even an approximation to thoroughness, is the work of a life, but as much as is needed for a sound comprehension of elementary physiological truths may be learned in a week.

A knowledge of the elements of physiology is not only easy of accuirement, but it may be made a real and practical acquaintance with the facts, as far as it goes. The subject of study is always at hand in oneself. The principal constituents of the skeleton, and the changes of form of contracting muscles, may be felt through one's own skin. The beating of one's heart, and its connection with the pulse may be noted ; the influence of the valves of one's own veins may be shown; the movements of respiration may be observed; while the wonderful phenomena of sensation afford an endless field for curious and interesting self-study. The prick of a needle will yield, in a drop of one's own blood, material for microscopic observation of phenomena which lie at the foundation of all biological conceptions; and a cold, with its concomitant coughing and sneezing, may prove the sweet uses of adversity by helping one to a clear conception of what is meant by "reflex action."

of course, there is a limit to this physiological selfexamination. But there is so close a solidarity between ourselves and our poor relations of the animal world, that our inaccessible inward parts may be supplemented by theirs. A comparative anatomist knows that a sheep's heart and lungs, or eye, must not be confounded with those of a man; but so far as the comprehension of the elementary facts of the physiology of circulation and of respiration and of vision goes, the one furnishes the needful anatomical data as well as the other.

Thus, it is quite possible to give instruction in elementary physiology in such a manner as not only to confer knowledge, which, for the reason I have mentioned, is useful in itself ; but to serve the purposes of a training in accurate observation, and in the methods of reasoning of physical science. But that is an advantage which I 
mention only incidentally as the present conference does not deal with education in the ordinary sense of the word.

It will not be suspected that I wish to make physiologists of all the world. It would be as reasonable to accuse an advocate of the "three R's" of a desire to make an orator, an author, and a mathematician of everybody. A stumbling reader, a pot-hook writer, and an arithmetician who has not got beyond the rule of three, is not a person of brilliant acquirements; but the difference between such a member of society and one who cannot either read, write, or cipher is almost inexpressible; and no one nowadays doubts the value of instruction, even if it goes no further.

The saying that a little knowledge is a dangerous thing is, to my mind, a very dangerous adage. If knowledge is real and genuine, $I$ do not believe that it is other than a very valuable possession, nowever infinitesimal its quantity may be. Indeed, if a little knowledge is dangerous, where is the man who has so much as to be out of danger?

If William Haryey's life-long labours had revealed to him a tenth part of what may be made sound and real knowledge to our boys and girls-he woukl not only have been what he was, the greatest physiologist of his age, but he would have loomed upon the seventeenth century as a sort of intellectual portent. Our little knowledge would have been to him a great, astounding, unlooked-for vision of scientific truth.

I really see no harm which can come of giving our children a little knowledge of physiolosy. But then, as I have said, the instruction must be real, based upon otservation, eked out by good explanatory diagrains and models, and conveyed by a teacher whose knowledge has been acquired by study of the facts, and not the mere catechismal parrot-work which too often usurps the place of elementary teaching.

It is, I hope, unnecessary for me to give a formal contradiction to the silly ficion, which is assiduously circulated by fanatics who not only ought to know, but do know, that their assertions are untrue, that I have advocated the introduction of that experimental discipline which is absolutely indispensable to the professed physio logist, into elementary teaching.

But while I should object to any experimentation which can justly be called painful, for the purpose of elementary instruction, and while, as a member of a late Royal Commission, I gladly did my best to prevent the infliction of needless pain for any purpose, I think it is my duty to take this opportunity of expressing my regret at a condition of the law which permits a boy to troll for pike, or set lines, with live frog bait, for idle amusement; and, at the same time, lays the teacher of that boy open to the penalty of fine and imprisonment if he uses the same animal for the purpose of exbibiting one of the most beautiful and instructive of physiological spectacles, the circulation in the web of the foot. No one could undertake to affirm that a frog is not inconvenienced by being wrapped up in a wet rag, and having his toes tied out; and it cannot be denied that inconvenience is a sort of pain. But you must not inflict the least pain on a vertebrated animal for scientific purposes (though you may' do a good deal in that way for gain or for sport) without due licence of the Secretary of State for the Home Department, granted under the authority of the Vivisection Act.

So it comes about, that in this present year of grace 1877 , two persons may be charged with cruelty to animals. One has impaled a frog, and suffered the creature to writhe about in that condition for hours; the other has pained the animal no more than one of us would be pained by tying strings round his fingers, and keeping him in the position of a hydropathic patient. The first offender says, "I did it because I find fishing very amusing," and the magistrate bids him depart in peace; nay, probably wishes him good sport. The second pleads, "I wanted to impress a scientific truth, with a distinctness attainable in no other way, on the minds of my scholars," and the magistrate fines him five pounds.

I cannot but think that this is an anomalous and not wholly creditable state of things.

\section{OUR ASTRONOMICAL COLUMN}

D'ARREST'S COMET. - M. Leverrier notifies the discovery of the periodical comet of I'Arrest by M. Coggia at Marseilles, on the 8th inst., nearly in the position assigned by $M$. Leveau's calculations. It was also detected at Florence by M. Tempel, on the Ioth.

The comet was discovered by the late Prof. D'Arrest at Leipsic on June 27, 185 I, and observed till October 6. The elliptical character of the orbit was pointed out by the discoverer early in August, and his conclusions were verified by the calculations of Vogel and Villarceau shortly afterwards, the latter astronomer commencing, while the comet was yet under obscrvation, a series of elaborate computations of the effect of planetary perturbations upon its motion, which were continued by him until taken up by Leveat. With the aid of Villarceau's ephemerides the comet was detected on its ensuing return to perihelion at the Royal Observatory, Cape of Good Hope, and observed from December 5,1857 , to January I8, I 858 . Oudemans, in a memoir published by the Royal Academy of Sciences at Amsterdam in 1854, had also carried forward the elements to this appearance, his results indicating that while the normal positions of 1851 were best represented by a mean motion which would bring the comet to perihelion again on December 5,1857 , there yet remained an uncertainty to the extent of eighty-five days in the length of the revolution. Villarceau, in the Comptes Rendus de l'Académie des scientes, 1852, December 6, considered the period fixed within narrower limits, one of his sets of elements assigning November 28,1857 , for the next perihelion passage, on which day the Cape observations show that it actually occurred. At the second reiurn in the spring of I864 the comet was not observed, and a very heavy work was involved in the preparation of an ephemeris for 1870 , owing to the large perturbations due to the action of Jupiter in $186 \mathrm{r}$, the comet having in April of that year approached the planet within 0.36 of the mean distance of the earth from the sun, and the two bodies remaining in proximity for a considerable time; it was therefore necessary to determine the effect of this near approach to the most powerful of the planets with every possible precision, a long work successfully accomplished by Leveau, who found on continuing the calculation of the perturbations of Jupiter, Saturn, and Mars, to June, 1870 , the following material changes in the elements at the perihelion passage in November, 1857.

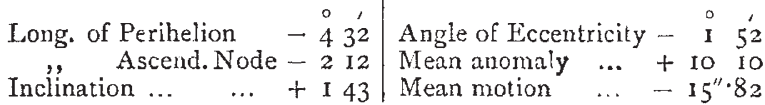
So that the period of rerolution was lengthened sixty. eight days, the comet arriving at perihelion on Septenuber 22,1870 . The effect of these perturbations was to alter the geocentric place at this time, no less than $14^{\circ .6}$ in right ascension, and $7^{\circ} 6$ in declination. At all three returns the comet has been a faint object, and it was particularly so in 1870 , when it was, nevertheless, sufficiently observed, Prof. Julius Schmidt, profiting by his favourable position at Athens, to follow it until nearly the end of the year.

The following are the dimensions of the orbit of D'Arrest's comet in the present year, according to the elements of Leveau.

Semi-axis major ... 3.54I39| Perihelion distance $\quad$ ×'31809 \begin{tabular}{rrr|lrr}
$r$ minor & $\ldots$ & $2.7565 \mathrm{I}$ & Aphelion & $\ldots$ & 5.76469 \\
Semi-parameter & $\ldots$ & 2.14559 & Eccentricity & $\ldots$ & 0.6275048
\end{tabular} 